\begin{tabular}{c} 
International Journal of Engineering \& Technology, 7 (3.6) (2018) 97-100 \\
International Journal of Engineering \& Technology \\
SPC \\
Website: www.sciencepubco.com/index.php/IJET \\
Research paper \\
\hline
\end{tabular}

\title{
Simulation Study on Variants of ABS
}

\author{
Srinivaas Ashok Kumar ${ }^{1 *}$, S. Thirumalini' ${ }^{2}$, P. Mohankumar ${ }^{3}$, R. Ram Sundar ${ }^{4}$, C. Aravind ${ }^{5}$ \\ ${ }^{I}$ Department of Mechanical Engineering, Amrita School of Engineering, Amrita Vishwa Vidyapeetham, Coimbatore, India. \\ ${ }^{2}$ Department of Mechanical Engineering, Amrita School of Engineering, Amrita Vishwa Vidyapeetham, Coimbatore, India. \\ ${ }^{3}$ Department of Mechanical Engineering, Amrita School of Engineering, Amrita Vishwa Vidyapeetham, Coimbatore, India. \\ ${ }^{4}$ Department of Mechanical Engineering, Amrita School of Engineering, Amrita Vishwa Vidyapeetham, Coimbatore, India \\ ${ }^{5}$ Department of Mechanical Engineering, Amrita School of Engineering, Amrita Vishwa Vidyapeetham, Coimbatore, India. \\ *Corresponding author E-mail:a_srinivaas@cb.amrita.edu
}

\begin{abstract}
The performance characteristics of different variants of Anti-Lock Braking System (ABS) in a normal passenger car is investigated. ABS prevent lock-up of wheels and maintains steer ability of the vehicle during braking. Vehicle stopping distance, brake pressure, wheel slip and slide-slip are made using Simulink software and system study was conducted an investigation is done. The variants of ABS taken for the study are 2-channel ABS (front wheels), Cross-ABS (alternate wheels: front left and rear right) and full (four channel) ABS. The Simulink model was interfaced with IPG Carmaker and simulation was performed to include the aerodynamics, tire friction and road friction. The results of the simulation were validated to obtain conclusions on the braking performance for different variants of ABS.
\end{abstract}

\section{Introduction}

Anti-lock Braking System(ABS) aids in the control of wheel during heavy braking. Braking severely on a slippery surface allows wheels to a lockup-condition at which pedal force reaches unit value and the slip is maximum at that point. At that instant $\mathrm{ABS}$ are activated and the brake line pressures of independent wheels are modulated irrespective of the pedal force and the wheel.

Speed is brought back to the non-slip condition thus enabling optimal braking and avoiding the slip condition. For our study, we have taken three variants of ABS-full ABS (four-channel), twochannel ABS (both channels to front individual wheels) and Cross-ABS (diagonally controlled-FL and RR). The Carmaker code provides a realistic simulation environment in which individually modelled car, road and driver interact to determine the vehicle dynamic characteristics like real world testing. Carmaker supports the extension of the models with Mat lab/ Simulink to facilitate the development and testing of enhanced vehicle control algorithms. The co-simulation environment of an extended carmaker-Simulink model has a pre-defined structure and is represented in Simulink as a nested multi-level model where the vehicle is subdivided into Simulink subsystems. Mat lab/Simulink brake model is interfaced with IPG Carmaker and various tests are carried out on ABS variants. Previously lots of work has been identified on simulation of a vehicle with ABS and without ABS. Here study has been made on the variants of $\mathrm{ABS}$ and on its properties governing on its brake performance.

Previously lots of work has been identified on simulation of a vehicle with $\mathrm{ABS}$ and without ABS. Here study has been made on the variants of $\mathrm{ABS}$ and on its properties governing on its brake performance.

\section{Experimental Setup}

A vehicle model with $1197 \mathrm{CC}$ engine size, wheel base of 2430 $\mathrm{mm}$ with front wheel drive (manual 5 speed transmission) and tire size of 165/80/R14 is considered for simulation. The ABS model was implemented in the IPG vehicle block of the Generic Car model under brake control. The ABS take input as the default torque for no-ABS and modifies the control strategy for braking torque. For different ABS variants, the links are interchanged in generic car model block and are interfaced with the IPG Carmaker and are made to run on test track with co-efficient of friction $(\mu)$ of asphalt surface as 1 and for Snow $\mu=0.4$ [1].

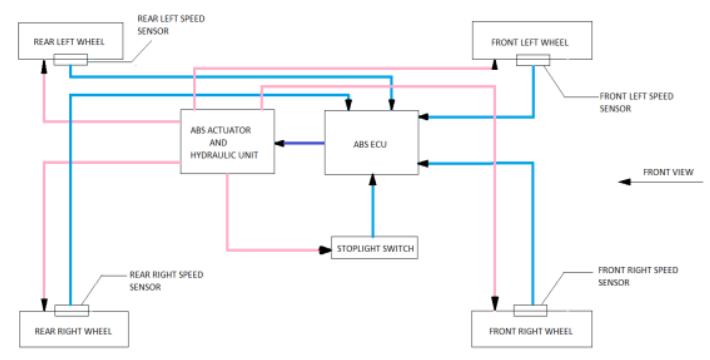

Fig. 1: Brake model for full ABS

Figure 1 represents the brake Model for full ABS configuration, all the four-wheel's pneumatic actuator actuating on the disc to brake are controlled by solenoid operated spool valves connected to the ABS control unit which has code program of responses activated from the signal input of wheel speed sensor and vehicle speed sensor. 


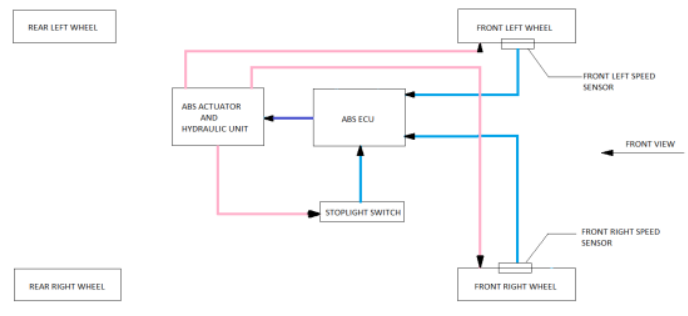

Fig. 2: Brake model for 2-Channel

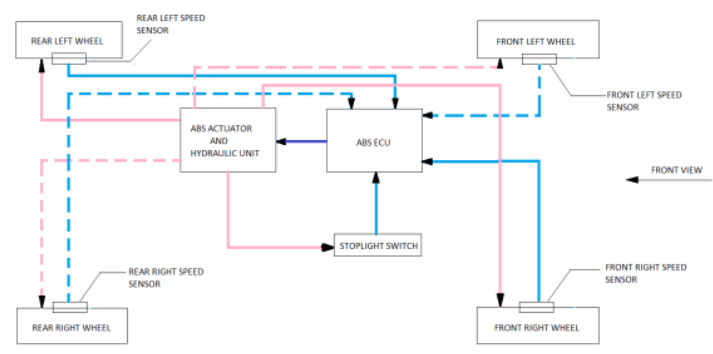

Fig. 3: Brake model for cross-channel

For 2-channel ABS, only one set of wheels related to the ABS control [2]. The links were connected as indicates in Figure 2 for the rear wheels and were other set of wheels were made to perform normal braking. For the Cross-ABS configuration, the ABS control model was linked with the front left and rear right wheels of the car as indicated in Figure 3.

\section{Vehicle Parameters}

The parameters for the elements of simulation were defined and includes modification of dimensions and parameters for car, load, road, traffic and environment.

Table I: Vehicle Specifications

\begin{tabular}{|l|l|}
\hline \multicolumn{1}{|c|}{ Specification } & \multicolumn{1}{c|}{ Value } \\
\hline Length & $3850 \mathrm{~mm}$ \\
\hline Width & $1695 \mathrm{~mm}$ \\
\hline Height & $1530 \mathrm{~mm}$ \\
\hline Wheel base & $2430 \mathrm{~mm}$ \\
\hline Track width (Front/Rear) & $1480 \mathrm{~mm} / 1485 \mathrm{~mm}$ \\
\hline Ground Clearance & $181 \mathrm{~mm}$ \\
\hline Un laden weight & $965 \mathrm{~kg}$ \\
\hline Engine size & $1197 \mathrm{cc}$ \\
\hline Fuel & Petrol \\
\hline Maximum power & $87 \mathrm{hp} @ 6000 \mathrm{rpm}$ \\
\hline Maximum torque & $115 \mathrm{Nm} @ 4500 \mathrm{rpm}$ \\
\hline Turning radius & 4.8 \\
\hline Drive type & Front wheel drive (FWD) \\
\hline Transmission & Manual 5-speed \\
\hline Tires & $165 / 80$ R14 \\
\hline
\end{tabular}

\section{Road and Motion Data}

Two types of road were selected for our simulation study of ABS. The types of road are normal asphalt road and another is the Snowy road where the operation of ABS played a much significant role. The road was created to resemble the actual road conditions by changing the general settings for the road. The coefficient of friction for asphalt was given as 1 . In which 0 denotes that the traction force in that type of road was good. The coefficient of friction $(\mu)$ for Snowy road was given as $0.4[1]$.

The motion of the vehicle was given in small maneuver steps. The parameters for the driver model like the cruising speed, gear shift speed and time gap between shifts were given. The motion consists of two maneuver steps- one step was accelerating to a cruising speed of 100 for 25 seconds and hard braking for 12 seconds. The braking operation was done by the pedal operation in which the brake pedal was pressed to its full pedal force (i.e. 1, maximum position)

\section{Results and Discussion}

The simulation was carried out for the three variants of ABS- full ABS, 2-channel ABS and Cross-ABS in normal asphalt road and Snowy road. The performance of the ABS variants was evaluated by comparing the following parameters

1. Stopping distance

2. Brake Pressure

3. Slip

4. Side slip

\section{Stopping Distance}

The distance travelled by the vehicle from applying of the brake to vehicle halt was calculated as stopping distance [1]. Stopping distance was deciding factor for choice snow of ABS in many situations. Hence the stopping distances for the different variants were compared under the two driving conditions.

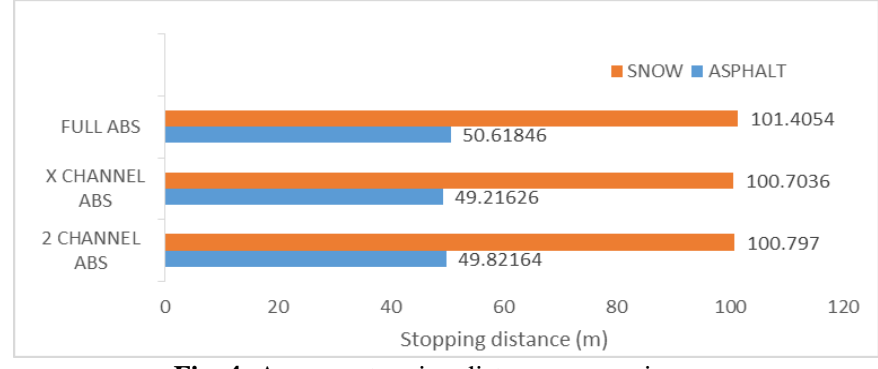

Fig. 4: Average stopping distance comparison

The vehicle is made to run at $100 \mathrm{~km} / \mathrm{hr}$. and given full brake pedal position for 25 seconds. The full ABS model variant has the stopping distance of 101.4054 which is $1.0934 \mathrm{~m}$ higher than $\mathrm{X}$ channel ABS and 0.6084 higher in 2 channel ABS compared to FULL ABS .This shows that FULL ABS variant takes a lot distance to stop as the ABS module works on to attain optimal range of slippage hence this stopping distance of FULL ABS variants is higher than the $\mathrm{X}$ channel and 2 -CHANNEL due to the desipitation of the heat energy generated from friction has to be desipitated by optimal control over the increasing rolling resistance of tire and road during braking condition [3]

\section{Brake Pressure}

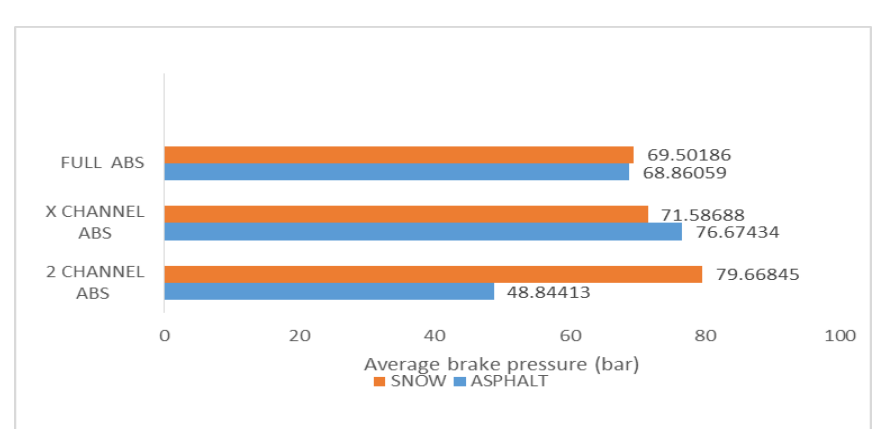

Fig. 5: Average brake pressure

Brake pressure is the amount of pressure that is transferred from controlling mechanism (brake pedal) to the brake mechanism. Figure 5 The average brake pressure for the 2-channel ABS was found to be 48.84413 the lowest for the asphalt road on the Snow road the pressure value is 79.66845 , the highest value among the Full ABS and 2-channal ABS. The other variants indicate that the 
ABS of 2 channel is comparatively not working significant than the FULL ABS which performs well on the Snow road providing a brake pressure of 69.50185 bar and the asphalt road of 68.86059 bar that maintains the pressure difference is less leading to good significant amount. Hence the pressure line of the brake wall at optimal level at all loading condition instead of varying in much pressure loading to fatigue condition of the hydraulic unit. The $\mathrm{X}$ channel ABS show higher pressure in asphalt condition that in Snow road with value of 71.58688 bar and 76.67434 bar due to configuration of the system itself.

\section{Slip}

Slip should be calculated from the wheel speed and vehicle speed. The slip values were between 0 and 1; 0 for stationary vehicle and 1 for wheels locked up during motion. During vehicle braking the slip should not go towards 1 as it might lead to skidding and damping of steerability [4]. This was found to be the major cause of accidents during panic braking.

The slip for 2-channel was found to be different for the two sets of wheels since ABS was connected to only a single set of wheels.

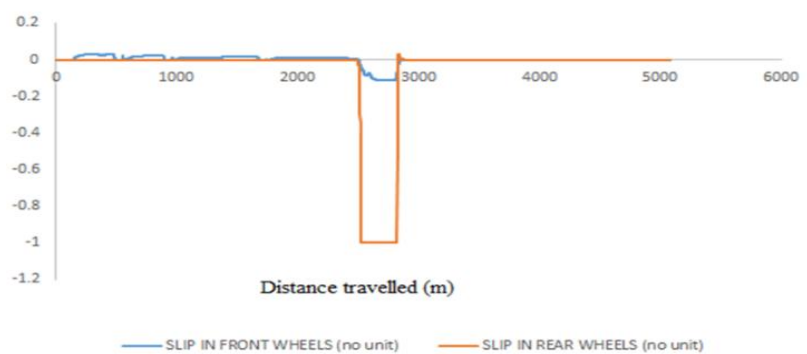

Fig. 6: Wheel Slip of 2-channel ABS in asphalt

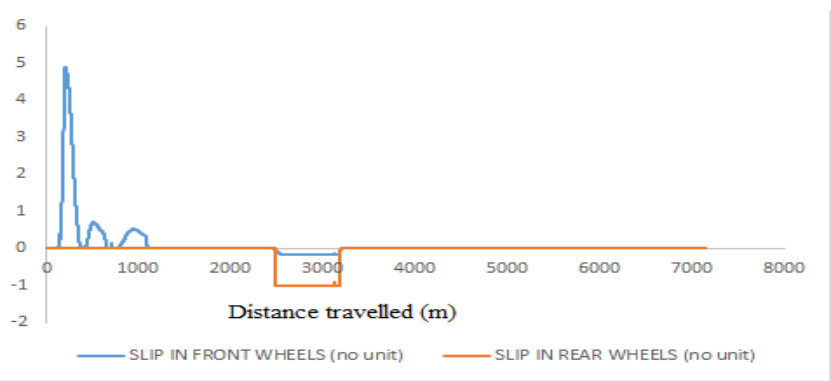

Fig. 7: Wheel slip of 2-channel ABS in snow

The average slip for this configuration was found to be maximum of $0.10(10 \%)$ at the rear wheel in the snow road surface $(\mu=0.4)$. The slip for the rear wheels reaches lock-up condition of slip 1 since they were not equipped with ABS. From Figure $6 \& 7$ the lock up time varies for asphalt and Snow road with the vehicle skidding more in the Snow road due to loss of traction. The spikes in the plot for Snow (Figure7) indicated the unpredicted starting acceleration behavior in Snow surface. Here in this simulation the wheel lock up condition happens and the wheel slides and travel more distance than the asphalt to the snowy road

In Cross-ABS the ABS control unit controls front- left and rearright wheels by one hydraulic control unit and front- right and rear- left by another hydraulic control unit

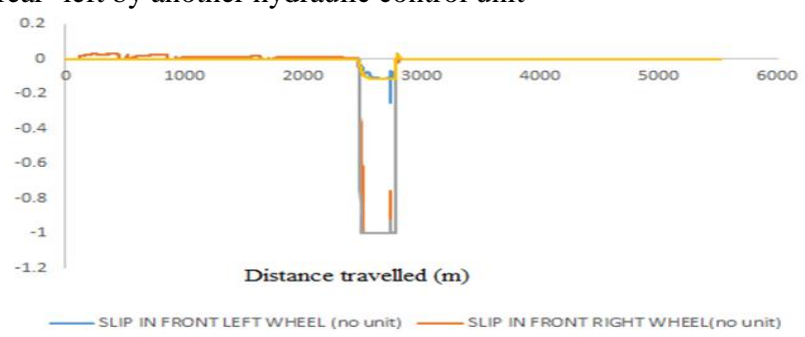

SLIP IN REAR LEFT WHEEL (nO uni) - SLIP IN REAR RIGHT WHEEL (nO unit)

Fig. 8: Wheel slip of cross-channel ABS in asphalt
The slip for the rear wheels reached 1 which indicated that the wheels locked-up and skidded. From Figure8, the skidding of the wheels was observed more in Snow road due to less friction between tire and road.

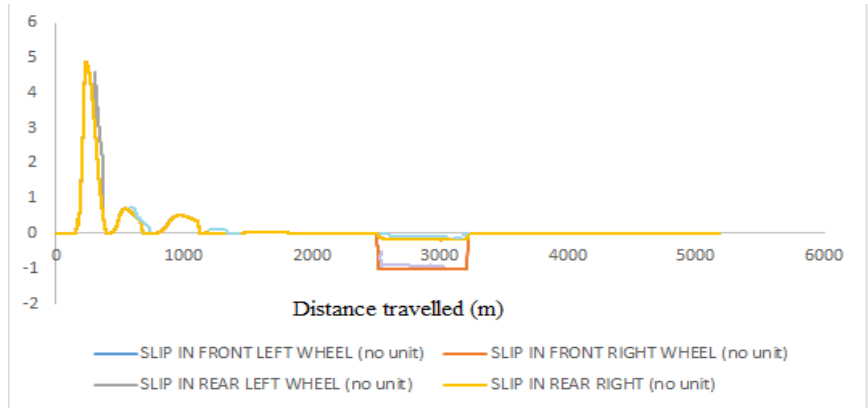

Fig. 9: Wheel slip of cross-channel ABS in snow

The ABS enabled wheels have an average value maximum of $0.13(13 \%)$ at the rear left wheel in the asphalt road $(\mu=1)$. The plot was drawn for all wheels since there was variation in individual wheels of the same axle.

In the full-ABS configuration, the individual wheels were controlled by the ABS control unit.

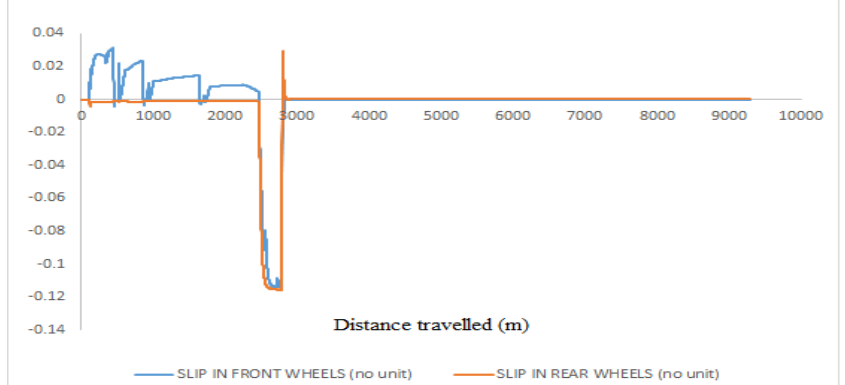

Fig. 10: Wheel slip of full CHANNEL ABS in asphalt

From, figure 10, full ABS no wheel reached the lock-up condition at any time. Hence it was concluded that the vehicle has never skid in this surface due to the ABS Control unit.

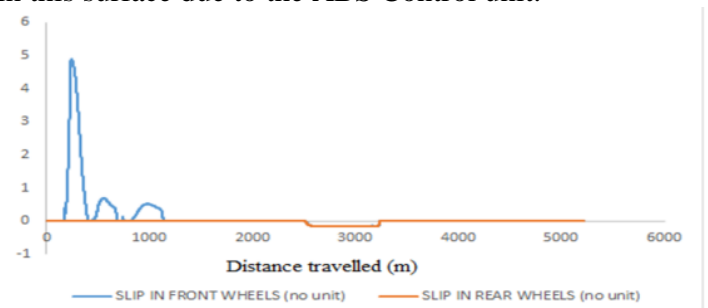

Fig. 11: Wheel slip of full channel ABS in snow

The average slip value for this configuration was found out to be maximum of $0.12(12 \%)$ at the rear wheel in the snow road $(\mu=0.4)$ leading to more travel in stopping distance providing stability control without wheel lock up condition.

\section{Side Slip}

Side slip angle can be defined as the angle between the velocity vector of vehicle and the horizontal axis of the vehicle.

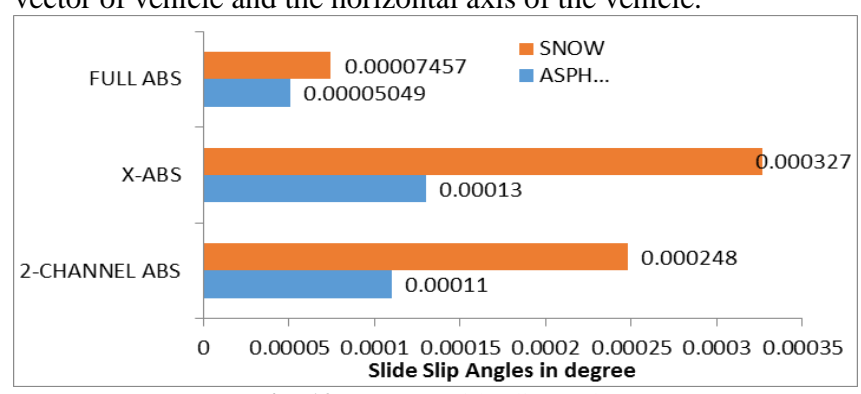

Fig. 12: Average side slip angle 
During heavy braking while travelling in a straight road, the direction of velocity vector changes which may cause the vehicle to skid sideways in slippery surfaces. Hence the sideslip angle for the different ABS braking was simulated and studied. From Figure 12 :The side slip angle at both the asphalt $(\mu=1)$ and snow $(\mu=0.4)$ for the Full ABS was found to be lowest which indicated that Full-ABS maintains the velocity direction during braking condition.

\section{Conclusion}

The simulation of test run for the different variants of ABS was carried out to study the braking performance of the vehicle. The plots for the different parameters for braking were examined to show the differences between the variants. The following conclusions were drawn from this project.

1. The stopping distance for the variants shows that the FULL ABS have longer stopping distance than other $X$ channel and 2 channel ABS variants due to the desipitation of the heat energy generated from friction must be desipitated by optimal control over the increasing rolling resistance of tire and the road during braking condition.

2. The Full ABS performs well on the asphalt and snow surfaces and maintains the pressure difference leading to less fatigue condition in hydraulic control unit.

3. The Full ABS does not reach the lockup condition value of 1 at any time. This indicates that the vehicle skidding is completely arrested in Full ABS and allows better steerability of the vehicle during panic braking condition.

4. The sideslip angle while braking is least for Full ABS. and shows that side slip of all variants did not affect the vehicle path drastically.

\section{References}

[1] Lee C, Hedrick K \& Yi K, "Real-time slip-based estimation of maximum tire-road friction coefficient", IEEE/ASME Transactions on mechatronics, Vol.9, No.2,(2004), pp.454-458.

[2] Infantini MB, Britto JFFH \& Perondi E, "Model of an ABS Pneumatic Regenerative Braking System (No. 2005-01-4033)". SAE Technical Paper, (2005).

[3] Petersen I, "Wheel Slip Control in ABS Brakes using Gain Scheduled Optimal Control with Constraints", ITK Report, 2003.

[4] Jain C, Abhishek R \& DixitLinear A, "Control Technique for AntiLock Braking System", www.ijera.com, Vol.4, No.8, (2014), pp.104-108.

[5] Zitzewitz P, Merrill Physics. Coefficient of friction for various surface, Principles and Problems New York: Glencoe, (1995). 